\title{
Prosthodontic Rehabilitation of a Case with Overlay Denture: A Case Report
}

\author{
Shak Mehta ${ }^{1}$ Manjit Kumar ${ }^{1} \quad$ Ajay Bansal ${ }^{1} \quad$ Ritu Batra $^{1} \quad$ Chhavi Sharma ${ }^{1}$ Sanjan Verma ${ }^{1}$ \\ ${ }^{1}$ Department of Prosthodontics, Bhojia Dental College, Solan, \\ Address for correspondence Manjit Kumar, MDS, Department of \\ Himachal Pradesh, India \\ Prosthodontics, Bhojia Dental College, Baddi 173205, Distt. Solan, \\ Himachal Pradesh, India (e-mail: manjitkiran@yahoo.co.in).
}

Dent J Adv Stud 2018;6:134-136

\begin{abstract}
Keywords

- bone preservation

- cast copings

- tooth retained

overdenture

A removable dental prosthesis that covers and rests on two or more remaining natural teeth, the roots of natural teeth, and/or dental implants is known as overdenture. This leads to less resorption of residual alveolar ridges. Restoration and modified teeth coronally can also be used as multiple abutments. In most cases, abutments are treated endodontically. In most patients with complete dentures, mandibular denture is difficult to adapt, and there is loss of retention because of less surface area. This case report represents prosthetic rehabilitation of a mandibular edentulous patient with cast coping with short dowels supported overdenture.
\end{abstract}

\section{Introduction}

A removable dental prosthesis that covers and rests on one or more remaining natural teeth, roots, and/or dental implants; a dental prosthesis that covers and is partially supported by natural teeth, tooth roots, and/or dental implants is known as overdenture. It is also known as overlay denture, overlay prosthesis, and superimposed prosthesis. ${ }^{1,2}$

The overdenture patient has better chewing efficiency as compared with conventional prosthesis. ${ }^{2}$ For better retention and preservation of alveolar bone, mandibular canines are preserved. $^{3}$

Treatment procedure includes endodontic treatment, periodontal consideration, caries management, location and distribution of abutment, and, most importantly, economy. Frequent recall visit and periodic fluoride application are of utmost importance.

\section{Case Report}

A 55-year-old patient reported to the Department of Prosthodontics, Bhojia Dental College \& Hospital, Bhud, Himachal Pradesh, with chief complaint of missing teeth. Loss of teeth was caused by caries and periodontal diseases.

On intraoral examination of the patient revealed completely edentulous maxilla, with partially missing mandibular arch. Only teeth present were 33, 34, and 43 (-Fig. 1).

On clinical and radiologic examination ( - Fig. 2), it was found that there was no mobility and periapical pathology. In 43 there was caries.

received

October 1, 2018

accepted after revision

November 30, 2018

published online

January 10, 2019
The patient wanted to get his teeth replaced for better mastication and esthetics.

\section{Treatment Plan}

Diagnostic impressions were made with impression compound (Rolex, Delhi, India) ( - Fig. 3). A tentative jaw relation was made on diagnostic cast to check interarch space. Sufficient space was available for short copings, but it was less for bar-supported overdenture.

Intentional endodontic treatment was done regarding 33,34 , and 43 . Teeth were prepared at equi-gingival margin in the form of chamfer finish line.

Preparation of post was done. Minimum $4 \mathrm{~mm}$ of apical seal was left. Custom cast posts were prepared with the help of bobby pin with light-body silicone (Zhermack, Badia Polesine, Italy) material injected into canal. Castings were made with base metal alloys (Hera P, Heraenium at cobalt chromium alloys, Heraeus Kulzer). Dome-shaped copings were made ( $\neg$ Fig. 4). Care should be taken that post should snugly fit into root canal and is finally cemented with glass ionomer cement (GC Fuji, Hyderabad, Telangana).

Primary impression with coping repeated again with impression compound. Custom trays were fabricated with polymethyl methacrylate (DPI, Delhi, India). Low-fusing compound was used to record borders for final impression (DPI Pinnacle; Mumbai, Maharashtra, India).

Secondary impression was made with zinc oxide eugenol impression (DPI Impression Paste, Mumbai, Maharashtra, India). 


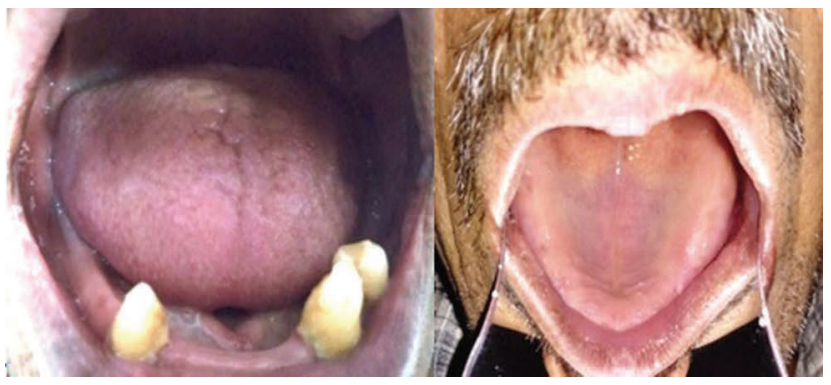

Fig. 1 Preoperative extraoral and intraoral views of patient.

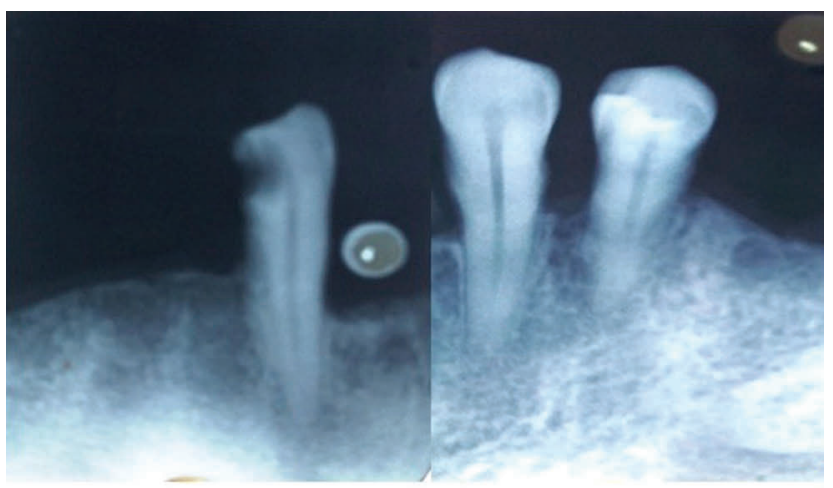

Fig. 2 Periapical radiographs.

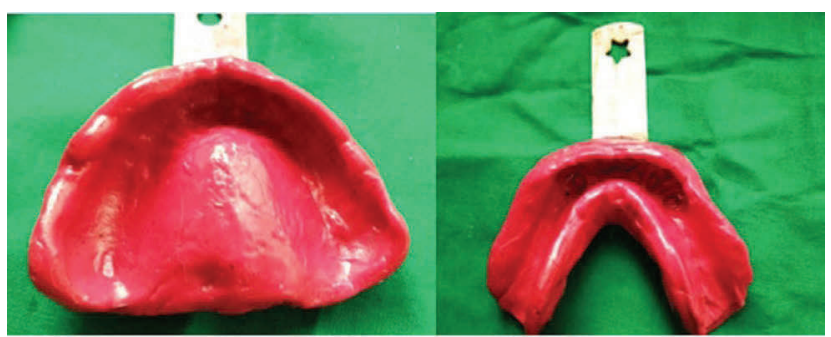

Fig. 3 Primary impressions.

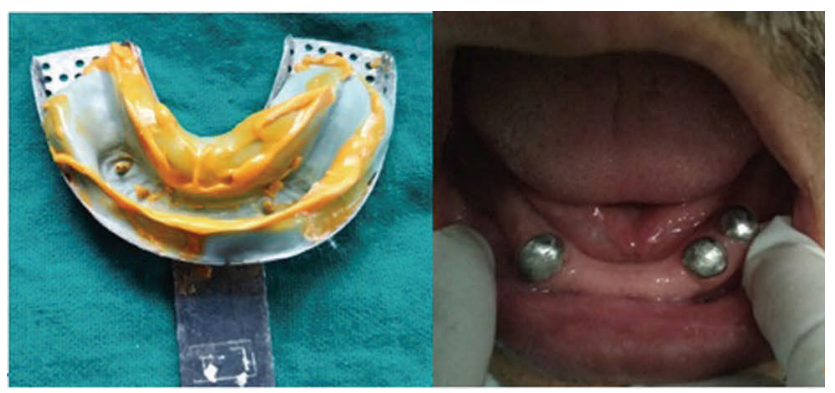

Fig. 4 Impression of post and coping cemented.

Mandibular secondary impression was made with light body impression material (Zermack, Italy). Master casts were made with type IV gypsum (Kalabhai, Mumbai, Maharashtra, India) (-Fig. 5).

Copings on the master cast were covered with wax (Rolex, Delhi, India), and record bases were fabricated. After this, occlusal rims were fabricated (-Fig. 6) and maxillomandibular relationship was recorded. Try-ins of the denture were done, and patient consent was taken for his approval and dentures were fabricated with conventional procedures with heat cure acrylic resin (Dentsply, Konstanz, Germany).
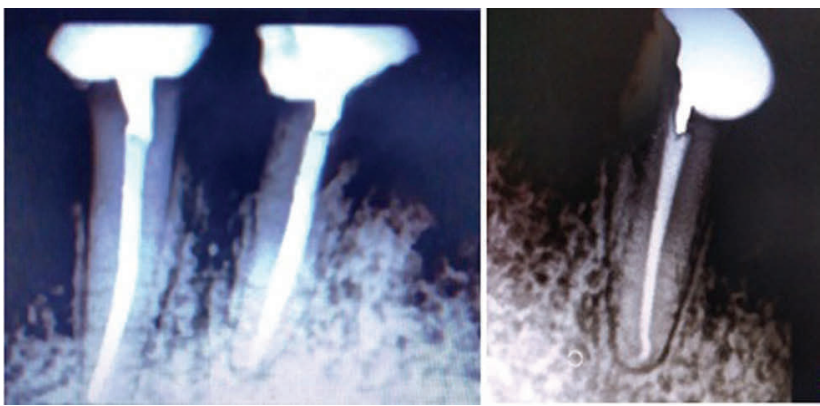

Fig. 5 Post-cementation radiographs.

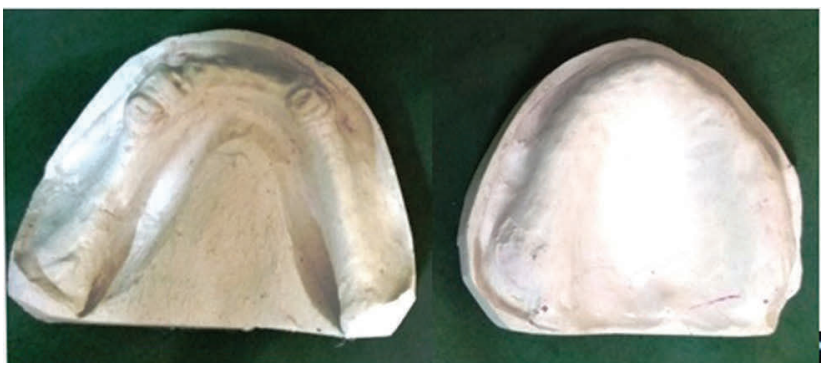

Fig. 6 Primary cast and secondary impression.

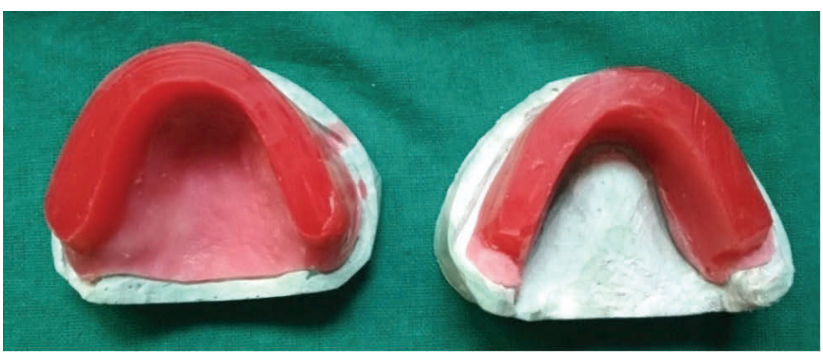

Fig. 7 Jaw relations.

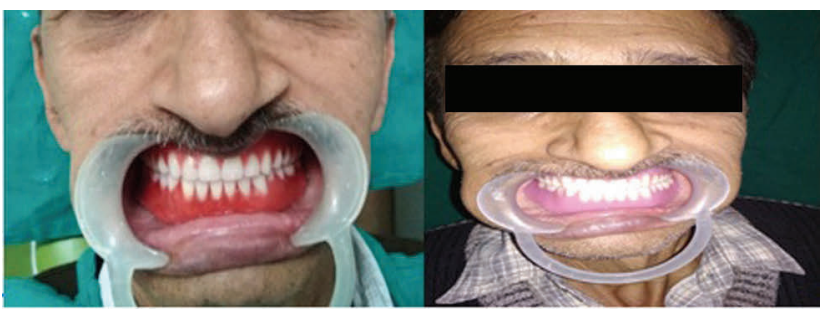

Fig. 8 Try-in and insertion.

Denture was inserted in the patient's mouth ( - Fig. 7). The patient was motivated and educated for oral hygiene measures, care of the denture, and for recall visit. Application of $0.4 \% \mathrm{SnF}$ was advocated to the patient.

The patient was much satisfied with retention of lower denture and for esthetics ( - Fig. 8).

\section{Discussion}

Overdenture has many advantages such as preservation of the alveolar bone, presence of proprioception, better retention, and stability of prosthesis. Moreover, vertical dimension of occlusion is maintained. These types of prosthesis are also fabricated in case of congenital defects such as oligodontia, 
cleft palate, and cleidocranial dyostosis. Over a period of time, the patient loses his retained teeth. In that case, it can be easily converted into conventional prosthesis.

A 5-year clinical study ${ }^{4,5}$ showed that patients treated with overlay denture had less bone resorption in mandibular/ maxillary dentures.

However, overdenture is expensive and bulkier, and maintenance is difficult and can lead to periodontal diseases.

Hartwell and Rahn ${ }^{6}$ have classified overdenture as coping type, noncoping type, with attachments, and with submerged vital or nonvital roots. Coping may be short $(2-3 \mathrm{~mm})$ or long (5-6 mm). Objective of copings is to improve the retention of prosthesis.

According to the study by Miller (1965), ${ }^{7}$ preserving the retained teeth for overlay denture helps in reducing the stress on residual alveolar ridge that reduces the resorption pattern.

The tactile thresholds on biting surfaces of teeth in case of natural dentition ranges from an average of $1 \mathrm{~g}$ on anterior teeth to $10 \mathrm{~g}$ on molar teeth, whereas in case of denture, threshold is found to be more than $125 \mathrm{~g}$ at the first premolar position. Therefore, it results in more resorption. ${ }^{8}$

\section{Conclusion}

Proper diagnosis and treatment plan, thorough examination and patient selection, skillfully executed laboratory procedures, and patient motivation and education are the foundations of preventive prosthodontics.

\section{Conflict of Interest}

None declared.

\section{References}

1 Prakash SV, Shivaprakash G, Hegde S, Nagarajappa. Four and two tooth supported-conventional over denture: two case reports. Int J Oral Health Sci 2013;3:61-64

2 Samra KR, Bhide VS, Goyal C, Kaur T. Tooth supported overdenture: a concept overshadowed but not yet forgotten! J Oral Res Rev 2015;7:16-21

3 Brewer AA, Morrow RM. Overdenture Made Easy. 2nd ed. St. Louis, MO: Mosby; 1980

4 Crum RJ, Rooney GE Jr. Alveolar bone loss in overdentures: a 5-year study. J Prosthet Dent 1978;40(6):610-613

5 Derkson GD, MacEntee MM. Effect of $0.4 \%$ stannous fluoride gel on the gingival health of overdenture abutments. J Prosthet Dent 1982;48(1):23-26

6 Hartwell CM Jr, Rahn AO. Syllabus of Complete Denture. 4th ed. Philadelphia, PA: Lee and Febiger; 1986

7 Miller PA. Complete dentures supported by natural teeth. Tex Dent J 1965;83:4-8

8 Manly RS, Pfaffman C, Lathrop DD, Keyser J. Oral sensory thresholds of persons with natural and artificial dentitions. J Dent Res 1952;31(3):305-312 